\title{
O turismo como impulsionador do mercado imobiliário em Crato (CE): um estudo no setor de hotelaria
}

\section{Tourism as market real estate in booster Crato (CE, Brazil): a study in the hospitality industry}

\author{
Francisca Kathyane Malheiros Lins, Antonio Fagundes Gomes da Silva, \\ Francisca Laudeci Martins Souza
}

\section{RESUMO}

O setor imobiliário está diretamente ligado à fatores econômicos locais favoráveis, que por sua vez, influenciam o espaço urbano e dinamizam a economia. Desse modo, este artigo pretende tratar inicialmente do investimento no setor imobiliário, a discorrer sobre bases conceituais acerca de investimentos e mercado imobiliário para entender melhor essa dinâmica de cunho econômico. O mercado enquanto local de agentes econômicos em movimento, estes estão submetidos à lei da oferta e da procura, onde num contexto dinâmico e contraditório capitalista subjugado a concorrência de mercado é preciso, para vencer os mercados globais e altamente competitivos, as organizações bem-sucedidas compartilham uma forte ênfase em inovação, aprendizado e colaboração. Buscamos identificar o comportamento dos investimentos no mercado imobiliário, num estudo de caso realizado no setor de hotelaria na cidade de Crato-CE, localizado na Região Metropolitana do CaririRMC. Nessa perspectiva, a cidade de Crato tem chamado a atenção por grande movimento turístico dos que vem presenciar o clima agradável da cidade localizada no sopé da Chapada do Araripe. Este fato tem movimentado o setor imobiliário na própria cidade e no entorno da Região Metropolitana do Cariri a qual está inserida, em especial, na área denominada CRAJUBAR, que abrange as cidades de Crato, Juazeiro do Norte e Barbalha. Estas cidades entraram num processo de conurbação e tem apresentado uma economia local dinamizada favorecendo a ampliação na rede de hotelaria. A região possui uma cultura ímpar de cores e sabores, de um povo cordial e natureza deslumbrante, que permite assim, com a sua diversidade cultural e atração turística, a promoção do desenvolvimento local que tem como apoio a Fundação Geopark Araripe. Assim, essa pesquisa é fundamentada em revisão bibliográfica acerca do mercado imobiliário e os fatores macroeconômicos que influenciam a investir no ramo, além da aplicação de questionários em hotéis na cidade de Crato para aquisição de dados primários. $O$ setor de hotelaria, como um empreendimento imobiliário comercial, tem sido um ramo favorável para investimentos dada uma localidade ser detentora de fatores econômicos, sociais, culturais e turísticos favoráveis. Os resultados mostraram que investir no setor de hotelaria do município, propicia a geração de empregos, assim como a mobilização de crescimento em outros setores, sobretudo do turismo, pois dinamiza as potencialidades da região em questão.

PALAVRAS-CHAVE: Mercado Imobiliário; Setor Hotelaria; Turismo. 


\section{ABSTRACT}

The real estate sector is directly linked to favorable local economic factors, which in turn influence the urban space and streamline the economy. Thus, this article intends to address your investment in real estate, to discuss conceptual basis about investments and real estate market to better understand this dynamic of economic developments. The market as a place of economic agents in motion, they are subject to supply and demand, which in a dynamic environment capitalist contradictory subdued market competition is necessary to overcome the global and highly competitive markets, successful organizations They share a strong emphasis on innovation, learning and collaboration. We seek to identify the behavior of investments in real estate, a case study in the hospitality sector in the city of Crato (CE, Brazil), located in the Metropolitan Region Cariri-RMC. In this perspective, the city of Crato has attracted the attention of large tourist movement coming witness the pleasant climate of the city located in the foothills of the Araripe. This fact has real estate busy in the city itself and around the metropolitan area of Cariri which is inserted, in particular in the area called Crajubar, covering the cities of Crato, Juazeiro and Barbalha. These cities have entered a conurbation process and has presented a streamlined local economy favoring the expansion in the hospitality network. The region has a unique culture of colors and flavors, a warm and beautiful nature people, thus allowing, with its cultural diversity and tourist attraction, the promotion of local development which has the support of Geopark Araripe Foundation. Thus, this research is based on literature review about the housing market and macroeconomic factors that influence to invest in the business, as well as questionnaires on hotels in Crato city for the purchase of primary data. The hotel industry as a commercial real estate development, has been a favorable field for investment given locality be the holder of economic, social, cultural and tourist friendly. The results showed that investing in the city's hotel industry, allows the creation of jobs, as well as the growing mobilization in other sectors, especially tourism, as streamlines the potential of the region in question.

KEYWORDS: Real Estate Market; Hospitality Industry; Tourism.

\section{Introdução}

O setor imobiliário é um mercado ativo que movimenta grandes investimentos. Está diretamente ligado a fatores econômicos locais favoráveis, como turismo, infraestrutura, renda, emprego, além da influência do resultado da dinâmica do espaço urbano e da economia.

Para que estes investimentos sejam realizados, várias decisões precisam ser tomadas. Uma das mais importantes decisões é o tempo ótimo para lançar no mercado, havendo várias incertezas relativas às condições de mercado, tais como os preços $/ \mathrm{m}^{2}$ dos imóveis e a velocidade das vendas, além das incertezas quanto ao investimento, como, por exemplo, o preço do terreno que varia ao longo do tempo para construção de edifícios comerciais e habitacionais, hotéis, entre outros.

Nesse contexto, este trabalho busca identificar o comportamento dos investimentos no mercado imobiliário, no setor de hotelaria na cidade de Crato, localizado na Região Metropolitana do Cariri-RMC. Quanto aos seus objetivos específicos, buscamos explicar os fatores macroeconômicos que influenciam o investimento nesta área, além de verificar a capacidade de 
investimentos no setor, com destaque para os principais hotéis do triângulo CRAJUBAR (Crato, Juazeiro do Norte e Barbalha) analisados na pesquisa.

Quanto aos procedimentos metodológicos, foi feita uma revisão bibliográfica acerca do mercado imobiliário e os fatores macroeconômicos que influenciam investimentos no ramo, além de aplicação de questionário no setor de hotelaria na cidade de Crato (CE), para aquisição de dados primários.

O trabalho foi dividido em quatro seções, além dessa introdução. Temos a segunda seção que discorre sobre bases conceituais acerca de investimentos e mercado imobiliário. A terceira seção busca mostrar o turismo como um fator essencial na tomada de decisão para investimentos no setor de hotelaria no triângulo CRAJUBAR, especificando a cidade de Crato (CE). A quarta seção apresenta um estudo de caso no setor de hotelaria tomando como território a cidade de Crato (CE). Por fim, tecemos algumas considerações finais acerca do trabalho.

\section{Investimento no Setor Imobiliário}

O investimento no setor imobiliário tem crescido nos últimos anos, influenciado por investidores que aplicam seus recursos buscando lucrar no longo prazo, e pessoas que buscam ter sua casa própria, atualmente facilitada por financiamentos bancários.

O mercado imobiliário é um campo importante para a economia mundial. No Brasil, o mercado imobiliário está em processo de aquecimento e vem sendo bastante valorizado, promovendo geração de emprego e renda, consequentemente elevação do nível de capital financeiro investido nesse setor. A hotelaria influenciada pelo crescimento da economia local se integra e altera diretamente a dinâmica urbana, social e econômica.

Nessa perspectiva convém discorrer sobre bases conceituais acerca de investimentos e mercado imobiliário.

\section{Mercado Imobiliário}

O mercado enquanto local de agentes econômicos em movimento significa um ambiente onde compradores e vendedores atuam na compra e venda de bens ou serviços, submetidos à lei da oferta e da procura. Mediante a concorrência de mercado, segundo Chiavenato (2003, p.570), "para vencer os mercados globais e altamente competitivos, as organizações bem-sucedidas compartilham uma forte ênfase em inovação, aprendizado e colaboração".

Os diversos ramos empresariais tem se preocupado em atender os desejos mais inusitados, necessidades e gostos pessoais de cada cliente. Esta tática tem diversificado aberturas comerciais de ofertas de bens e serviços numa enorme variedade, entretanto, cresce também na mesma medida os riscos em atividades empresariais devido à rápida mudança de gostos e de produtos e serviços defasados. Para Chiavenato (2003, p. 44): 
O desenvolvimento de produtos ou serviços exigirá maiores investimentos em pesquisas e em desenvolvimento, aperfeiçoamento de tecnologias, dissolução de velhos e criação de novos departamentos, busca incessante de novos mercados e competição com outras organizações para sobreviver e crescer.

A partir dessa visão geral de mercado, se afunilará bases conceituais referentes ao mercado imobiliário.

O mercado imobiliário, por sua vez, é composto pelos seguintes agentes: imobiliárias, corretoras de imóveis autônomas, o profissional corretor, proprietário, empreiteiras de mão de obra, empresas da construção civil e empresas prestadoras de serviços em propaganda e marketing, que atuam nas atividades de administração e comercialização dos empreendimentos imobiliários (MATOS; BARTKIW, 2013). Podemos dizer então, que mercado imobiliário e construção civil estão intrinsicamente ligados, oportunizando e gerando possibilidades de geração de emprego e renda.

A construção civil é um dos setores que mais crescem com relação à participação na ocupação total de pessoas, principalmente na virada da década dos anos 2000.

O número de trabalhadores com carteira assinada cresceu $95,2 \%$ entre 2003 e 2011. No mesmo período, na média dos demais setores, a população ocupada com carteira cresceu muito menos - 48,2\%, segundo o Instituto Brasileiro de Geografia e Estatística (IBGE). A falta de mão de obra no setor fez com que empresas tomassem iniciativas para reter seus trabalhadores e, a mão de obra, ciente da sua valorização, passou a exigir maiores benefícios (ASSOCIAÇÃO DE DIRIGENTES DE EMPRESAS DO MERCADO IMOBILIÁRIO, 2012, p.1).

O setor imobiliário tem sido uma boa forma de investir dinheiro, sendo um patrimônio durável e que se valoriza ao longo prazo, especialmente quando ocorrem melhorias na infraestrutura da região. Assim, a construção civil em 2012, passa a ser a novidade no mercado imobiliário mundial, 0 Brasil se torna o segundo lugar mais atraente para investidores estrangeiros, superando a Europa e a China, apontando São Paulo como a quarta cidade mundial mais atraente para aplicações em imóveis (ASSOCIAÇÃO DE DIRIGENTES DE EMPRESAS DO MERCADO IMOBILIÁRIO, 2012, p.1).

Logo, os investimentos destinados ao setor imobiliário, atualmente valorizado, proporcionaram abertura de novos empreendimentos habitacionais e comerciais como casas, edifícios comerciais, hotelaria, centros comerciais, atacadistas, varejistas, bancos, salas comerciais, farmácias, padarias, supermercados, materiais de construção. Assim, seguimos um estudo mais específico no ramo de hotelaria, na cidade de Crato (CE). 


\section{Metodologia}

\section{Área de Estudo}

O setor de hotelaria na cidade de Crato-CE tomou-se como centro dessa pesquisa, visto que essa localidade se destaca no dinamismo de ocupação por turistas, em função de ser uma região favorecida por seu clima de oásis e por englobar um deslumbrante ambiente natural e histórias culturais marcantes.

\section{Fonte Dos Dados}

Foi utilizado nesta pesquisa dados primários e secundários. Os dados de natureza primária foram obtidos a partir da pesquisa de campo e aplicação de questionários realizados junto aos proprietários do estabelecimento ou, na ausência destes, aplicados aos recepcionistas. Já os dados secundários, foram obtidos a partir de revisão bibliográfica buscando traçar de forma coesiva o mercado imobiliário e os fatores macroeconômicos que influenciam a investir no ramo de empreendimento em hotelaria.

\section{Métodos De Análise}

O trabalho foi desenvolvido no setor de hotelaria em Crato (CE). Sendo que para alcançar os objetivos propostos, pautamo-nos por uma atuação em campo fundamentada pela pesquisa participante que Brandão (1981), indica como minimizadora do hiato entre o sujeito do conhecimento e seu objeto de estudo. Orientando-nos pela perspectiva etnográfica que segundo Ezpeleta e Rockwell (1986), parte da confrontação entre a teoria e a realidade observada, identificando a reconstrução dos valores sob os quais os sujeitos determinam suas práticas.

\section{Setor de Hotelaria em Crato (CE): Uma Visão a partir do Turismo para o Investimento}

A construção de moradias voltadas exclusivamente para o uso próprio de morar, conviver e permanecer passa a dar lugar também aos empreendimentos comerciais, conforme o novo sistema que permeia, como um meio necessário. Assim, o setor de hotelaria, como um empreendimento imobiliário comercial, tem sido um ramo favorável para investimentos dada uma localidade ser detentora de fatores econômicos, sociais, culturais e turísticos favoráveis.

O vice-presidente da área imobiliária do SINDUSCON (Sindicado das Construtoras do Ceará) Ceará, André Montenegro, sinaliza que, pela falta de estrutura das cidades, o crescimento imobiliário dos municípios cearenses ainda encontra-se reprimido. Colabora o diretor do Conselho Federal de Corretores de Imóveis (COFECI), Armando Cavalcante, para as razões de tais investimentos serem apontadas na região do Cariri: "Os motivos profissionais, acadêmicos e o turismo em especial o religioso tem 
contribuído para o crescimento da migração para cidades do interior e isto tem movimentado o setor imobiliário" (FORTES, 2012).

Nessa perspectiva, a cidade de Crato tem chamado a atenção por grande movimento turístico dos que vem presenciar o clima agradável da cidade localizada no sopé da Chapada do Araripe. Este fato tem movimentado o setor imobiliário na própria cidade e no entorno da Região Metropolitana do Cariri a qual está inserida, em especial na área denominada CRAJUBAR, que abrange as cidades de Crato, Juazeiro do Norte e Barbalha. Estas cidades entraram num processo de conurbação e tem apresentado uma economia local dinamizada, favorecendo a ampliação na rede de hotéis.

A região possui uma cultura ímpar de cores e sabores, de um povo cordial e natureza deslumbrante, permite assim, com a sua diversidade cultural e atração turística promover o desenvolvimento local que tem como apoio a Fundação Geopark Araripe, este inserida na Rede Global de Geoparques, como um projeto de desenvolvimento socioeconômico mais importante do Governo do Estado do Ceará.

A sede do Geopark fica em Crato, próximo à Universidade Regional do Cariri- URCA e Parque de Exposição, pois por está muito próxima da Chapada do Araripe, propicia atividades ligadas ao ecoturismo, turismo de aventura, prática de esportes radicais, geoturismo e oferece vários equipamentos de lazer, como: balneários, clubes, chalés, entre outros, assim, a cidade reflete um potencial de crescimento econômico gerado por este.

O Geopark Araripe é uma fundação que preza pelos territórios que são patrimônio geológico, denominado geossítios, que são áreas com limites definidos, que possuem grande valor científico, histórico, cultural e ambiental. Um dos principais programas do Geopark é a educação ambiental, voltada para a integração das comunidades do território à estratégia de desenvolvimento, através do fortalecimento social e conservação do patrimônio natural e cultural.

Logo, é crescente a quantidade de visitantes na região para conhecer os geossítios, buscando reconhecer o importante valor desse rico patrimônio natural. Esse fato tem favorecido os investimentos no setor de hotéis, na perspectiva de atender a necessidade dos visitantes à região, tornando este ramo atraente para investidores e possibilitando 0 empreendedorismo local.

\section{Setor de Hotelaria: O empreendedorismo}

A fim de atender a demanda turística e satisfazer as necessidades advindas de pessoas por trabalho, turistas por lazer, ampliou-se o ramo de hotelaria na região.

O turismo de negócio, conforme Silva (2004) tem elevada importância para uma cidade ou região, e, por consequência, a todo o país, porém, ainda tem um vasto campo a ser explorado, incentivando o desenvolvimento socioeconômico local, contribuindo para a geração de empregos, renda, e 
criação de infraestrutura que beneficia não só o turista, como as localidades receptoras.

O triângulo CRAJUBAR é um dos que mais está crescendo na área imobiliária. Na opinião do presidente do Conselho Regional de Corretores de Imóveis do Ceará - CRECI/CE, Armando Cavalcante, "é um mercado altamente promissor, com ofertas de condomínios de casas, loteamentos e prédios, com o início de um processo de verticalização", explica ele. De acordo com Marinho (2009), "Além de edifícios residenciais, um centro empresarial está sendo construído".

A partir do site booking que avalia os serviços da rede de hotelaria, os principais hotéis que recebem turistas no triângulo CRAJUBAR são os seguintes (Quadro 1):

Quadro 1: Principais hotéis- CRAJUBAR (Crato, Juazeiro do Norte e Barbalha).

Table 1: Main hotel - CRAJUBAR (Crato, Juazeiro do Norte and Barbalha - CE, Brazil).

\begin{tabular}{|c|c|c|}
\hline Hotel & Nível de avaliação & Município \\
\hline lu-á Hotel & Fantástico $(9,0)$ & Juazeiro do Norte \\
\hline Hotel das Fontes & $\operatorname{Bom}(7,7)$ & Barbalha \\
\hline Imperial Palace Hotel & $\operatorname{Bom}(7,6)$ & Juazeiro do Norte \\
\hline Panorama Hotel & $\operatorname{Bom}(7,4)$ & Juazeiro do Norte \\
\hline Hotel Brisa da Serra & $\operatorname{Bom}(7,3)$ & Crato \\
\hline Hotel Pasargada & $\operatorname{Bom}(7,1)$ & Crato \\
\hline Verdes Vales Lazer Hotel & 6,9 & Juazeiro do Norte \\
\hline Pousada Lagoa Seca & 6,7 & Juazeiro do Norte \\
\hline Canavial Plaza Hotel & 6,5 & Barbalha \\
\hline Lagoa Lazer Hotel & 6,4 & Juazeiro do Norte \\
\hline Pousada Santo André- Apóstolo & não consta (novo) & Juazeiro do Norte \\
\hline \begin{tabular}{|l} 
Santa Rosa Hotel \\
\end{tabular} & não consta & Juazeiro do Norte \\
\hline Pousada Sítio Pinheiros & não consta & Barbalha \\
\hline
\end{tabular}

Fonte: Elaboração própria, a partir de dados do site do Booking (2014).

Source: Own elaboration, based on data from the Booking website (2014).

Percebemos pelo quadro acima apresentado, que o lu-á Hotel, inaugurado em novembro de 2013 , se destaca pela avaliação $(9,0)$. De acordo com os dados apurados na pesquisa, esse hotel recebe turistas que chegam a negócios, como empresários e representantes de empresas. Vindos de outros estados, como São Paulo, Recife, Belo Horizonte, Paraíba, Fortaleza e de outros países, como: Estados Unidos, Nova Zelândia, entre outros. Além disso,o hotel chama a atenção por possuir uma ótima estrutura e também por haver parceria com o Geoparque Araripe, oferecendo aos turistas uma visita pelos geossítios da Região do Cariri, um grande diferencial aos demais.

Diante de tudo que foi exposto, é visível que estamos diante de uma região promissora, que tem se desenvolvido cotidianamente a partir da dinamização do comércio, turismo e cultura. Logo, pretendemos adiante 
identificar os investimentos no mercado imobiliário no setor de hotelaria tomando como território a cidade de Crato (CE).

\section{Hotelaria: Estudo de Caso em Crato (CE)}

Crato é uma cidade privilegiada por seus recursos ambientais e potencialidades hídricas, uma vez que, propicia o desenvolvimento agrícola, podendo diversificar a sua base de produção e expandir a agricultura, tornando-a um polo central para a dinâmica econômica da região.

Conforme Amora (1989), Crato destacou-se por seu nível de intelectualidade e política, constituindo-se como um município forte a influenciar estados vizinhos, sendo município polo da região sul do Estado, reorganizando o espaço local e estabelecendo constantes fluxos migratórios inter-regionais.

Outrora, Crato afirma-se como um importante centro urbano, como pioneiro de um centro comercial em expansão para a região, atraindo comerciantes e prestadores de serviços, em ocasião da decadência do excepcional comércio cearense, da cidade de lcó (BESERRA, 2006).

\footnotetext{
O município do Crato, reconhecido como importante centro regional cearense, estando localizado no centro da Chapada do Araripe. Limita-se ao Norte e Nordeste com os municípios de Farias Brito, Várzea Alegre e Caririaçu; ao Sul e Sudoeste com os municípios de Moreilândia e Exú, no Estado de Pernambuco; ao Leste e Sudeste com os municípios de Juazeiro do Norte e Barbalha e ao Oeste e Noroeste com os municípios de Nova Olinda e Santana do Cariri. Os distritos que compõem o Município são: Crato, Baixio das Palmeiras, Bela Vista, Belmonte, Campo Alegre, Dom Quintino, Monte Alverne, Ponta da Serra, Santa Rosa e Santa Fé (OLIVEIRA; ABREU, 2010, p. 247).
}

A cidade de Crato continua crescendo, mesmo tendo o município do Juazeiro do Norte um grande concorrente frente aos setores de serviços e comércio, conforme a hierarquia dos polos centrais da região. "Assim mesmo, apesar de não ser mais a capital do Cariri, a cidade do Crato não parou de crescer, principalmente em virtude de ainda ser um centro importante de produção e por deter influência do ponto de vista educacional e turístico na região" (OLIVEIRA, 1998, p. 62).

Da necessidade de compreender o dinamismo de investimento no setor de hotelaria no município de Crato, foi listado os 10 principais hotéis e pousadas em funcionamento e ocupados por turistas que são em maior quantidade, provenientes da própria região do nordeste (Quadro 2), com a devida data de inauguração do empreendimento e número de leitos. 
Quadro 2: Principais hotéis do município de Crato (CE).

Table 2: Main hotels in the municipality of Crato (CE).

\begin{tabular}{|c|c|c|}
\hline POUSADAS E HOTĖIS- CRATO/CE & $\begin{array}{c}\text { ANO DE } \\
\text { INAUGURAÇÄO }\end{array}$ & QUANT. DE LEITOS \\
\hline POUSADA PORTO BELO & 2003 & 11 \\
\hline POUSADA SÃO MIGUEL & 2008 & 24 \\
\hline $\begin{array}{c}\text { POUSADA E PENSIONATO } \\
\text { ALENCAR }\end{array}$ & 1986 & 12 \\
\hline $\begin{array}{c}\text { POUSADA E MARMITARIA Pe. } \\
\text { CÍCERO }\end{array}$ & 2013 & 13 \\
\hline $\begin{array}{c}\text { POUSADA SAGRADA FAMÍLIA } \\
\text { HOTEL VILLA REAL }\end{array}$ & 2000 & 41 \\
\hline $\begin{array}{c}\text { HOTEL ENCOSTA DA SERRA } \\
\text { PASÁRGADA HOTEL }\end{array}$ & 1994 & 41 \\
\hline HOTEL BRISA DA SERRA & 2002 & 40 \\
\hline HOTEL PORTAL DO CRATO & 2000 & 90 \\
\hline
\end{tabular}

Fonte: Elaboração através de dados primários da pesquisa de campo (2016). Source: Elaboration through primary field research data (2016).

Como se verifica, são dez (10) estabelecimentos, divididos em hotéis e pousadas, apontando que, a Pousada e Marmitaria Pe. Cícero é vinculada com outra de nome Recanto do Cariri, por serem do mesmo proprietário, porquanto, são próximas, situadas na mesma rua, e cada uma contém 06 leitos.

Pela data de inauguração, percebemos que entre as mais antigas, a Pousada e Pensionato Alencar e o Hotel Villa Real, passaram por um processo de modernização ao longo dos anos, a fim de se adaptarem as novas demandas. Sendo de estabelecimento próprio e prezando sempre pelo bom atendimento, são situadas no centro da cidade de Crato, recebendo clientes de várias localidades, até mesmo estrangeiros, porém demasiadamente do estado do nordeste. Sobretudo, a participação dos clientes no faturamento, tanto na alta, como na baixa temporada, são à negócios.

A ocupação dos clientes no setor de hotelaria do município é a quem vem a negócios, a eventos ou ao lazer. Entretanto, a maior taxa verificada para a alta temporada, é a negócios e a eventos, esta alta temporada, ou época alta é, o período em que os destinos turísticos recebem um maior fluxo de visitantes, sobretudo no mês de julho, período da festividade da 
Expocrato. A Expocrato é uma das maiores exposições centro-nordestinas de animais e produtos derivados (BLOGDOCRATO, 2013). O crescimento da festa a cada ano é bem visível e consegue se destacar no cenário estadual como a maior feira agropecuária do Ceará, a segunda maior do Nordeste, depois de Salvador, e está entre as cinco maiores do Brasil, conforme consta Francisco Leitão Moura, presidente do Grupo Gestor da Expocrato, em 2012.

A cadeia de hotéis e restaurantes tem o seu maior faturamento nesta época do ano. Praticamente todos estão lotados, com reservas que acontecem de forma antecipada.

A Expocrato também contribui para a comercialização de animais, com a exposição de diversos rebanhos, vindos de regiões mais distantes, como o Sudeste. Também transforma o evento numa vitrine, com empresas especializadas na comercialização de máquinas e implementos agrícolas, dentre outros empreendimentos.

$\mathrm{Na}$ baixa temporada, a ocupação dos hotéis, sobretudo das pousadas, que tem por duração média de tempo no estabelecimento, de um a três dias, se dá por turistas que vem apreciar os valores culturais da região, assim como, a riqueza ambiental de uma natureza deslumbrante, permitindo a estes o contato direto com a Serra da Chapada do Araripe, possibilitando ambientes de lazer nos arredores da cidade de Crato, como: balneários, clubes e chalés.

A pousada Porto Belo, a pousada São Miguel, o hotel Encosta da Serra e o hotel Brisa da Serra, oferecem aos seus hóspedes indicações de guias de turistas para a visitação da chapada do Araripe e passeio aos geoparques. Assim como também alguns deles trabalham em parceria no trade turístico, como a Pousada Porto Belo, apresenta uma parceria com as agências de turismo, ABRASEL (Associação Brasileira de Bares e Restaurantes), e a mesma parceria com o hotel Brisa da Serra, havendo parcerias também com guias e com o geoparques.

A pousada São Miguel não trabalha com estas parcerias, no entanto, propicia o conhecimento dos geossítios, por meio de indicação de guias turísticos que possam apresentar a visita a estes espaços.

O hotel Encosta da Serra trabalha com parcerias também, com guias de turismo, propiciando aos clientes atividades esportivas, como o rapel, no próprio ambiente da chapada.

As parcerias com o trade turístico não é incluso ao pagamento da hospedagem, uma vez que, acontece pelo próprio interesse do cliente a procurar conhecer de perto as belezas e a rica diversidade ambiental, cultural e histórica.

Os hotéis e pousadas do município de Crato apresentam características diversificadas, desde sua infraestrutura, localização e mesmo o preço da diária estabelecido por cada estabelecimento, assim distribuído nas suas variações, conforme o quadro seguinte (Quadro 3): 
Quadro 3: Variações dos preços da diária das pousadas e hotéis do município de Crato (CE). Table 3: Changes in daily prices of inns and hotels in the municipality of Crato (CE).

\begin{tabular}{|c|c|c|}
\hline POUSADAS E HOTĖIS- CRATO/CE & $\begin{array}{l}\text { PREÇO DA DIÄRIA } \\
\text { MINIMO (R\$) }\end{array}$ & $\begin{array}{c}\text { PREÇO DA DIÄRIA } \\
\text { MÄXIMO (R\$) }\end{array}$ \\
\hline POUSADA PORTO BELO & 70,00 & 70,00 \\
\hline POUSADA SÃO MIGUEL & 35,00 & 100,00 \\
\hline $\begin{array}{l}\text { POUSADA E PENSIONATO } \\
\text { ALENCAR }\end{array}$ & 50,00 & 50,00 \\
\hline $\begin{array}{l}\text { POUSADA E MARMITARIA Pe. } \\
\text { CÍCERO }\end{array}$ & 30,00 & 30,00 \\
\hline POUSADA SAGRADA FAMÍLIA & 30,00 & 35,00 \\
\hline HOTEL VILLA REAL & 132,00 & 227,00 \\
\hline HOTEL ENCOSTA DA SERRA & 175,00 & 367,00 \\
\hline PASÁRGADA HOTEL & 184,00 & 356,00 \\
\hline HOTEL BRISA DA SERRA & 120,00 & 300,00 \\
\hline HOTEL PORTAL DO CRATO & 80,00 & 260,00 \\
\hline
\end{tabular}

Fonte: Elaboração através de dados primários da pesquisa de campo (2016). Source: Elaboration through primary field research data (2016).

A partir do quadro acima, constatamos que a Pousada Porto Belo, a Pousada e Pensionato Alencar, a Pousada e Marmitaria Pe. Cícero mantém um preço fixo em suas diárias. Desse modo, os preços não sofrem ajustes, e permanece o mesmo valor, tanto na alta, como na baixa temporada.

Conforme o preço estabelecido, segundo os entrevistados dos hotéis e das pousadas, as variações de preços ocorrem, como indica tais variações em alguns destes hotéis e pousadas citadas, devido manutenções no estabelecimento, do tipo de qualidade do quarto, do seu tamanho, alocado pela quantidade de pessoas a se hospedar, tal qual, individual, duplo, triplo. Os preços destes sofrem ajustes no período da alta temporada.

Todos estes estabelecimentos de hotelaria oferecem aos hóspedes o café da manhã incluso ao pagamento. Portanto, vale tratar especificamente a vantagem que cada um proporciona ao seu hóspede, para que o mesmo venha a retornar.

Pela localização central da cidade, nas proximidades do comércio, qualidade no atendimento e serviços, preços satisfatório, ou seja, acessível, temos o Hotel Villa Real, a Pousada e Pensionato Alencar, Pousada e Marmitaria Pe. Cícero / Recanto do Cariri, Pousada Sagrada Família, Pousada Porto Belo e Pousada São Miguel, sendo este último, a não disponibilizar garagem. 
O Hotel Portal do Crato, proporciona o uso da piscina pelos hóspedes e estacionamento, e por está localizado aproximadamente a $2 \mathrm{~km}$ do centro da cidade, aconchega seus hóspedes num ambiente de tranquilidade.

O Hotel Brisa da Serra por está localizado no sopé da serra, oferece um clima agradável e uma bela vista do Triângulo CRAJUBAR - Crato, Juazeiro do Norte e Barbalha; e da Chapada do Araripe. No café da manhã seus lanches e pratos são tipicamente com delícias regionais. O Hotel também disponibiliza de espaços a serem alugados para festas, eventos, aniversários, casamentos, recepções, feiras, encontros, camping, reuniões. O grande diferencial aos demais é o fato dos hóspedes poderem levar seus animais de estimação. E por sua ampla estrutura, dispõe também de estacionamento.

Contando com estacionamento e piscinas, o Pasárgada Hotel, encontra-se numa localização de clima agradável e aconchegante, com a possibilidade de um maior contato com a natureza. O Hotel também funciona como balneário, nos finais de semana, uma vez que, o valor cobrado da entrada é totalmente descontado no valor do consumo. Dispõe também de academia, aluguel de espaço físico e promovem eventos, investimentos que geram uma renda a mais no faturamento do hotel.

O Hotel Encosta da Serra, permite uma visão panorâmica da Chapada do Araripe, com clima aconchegante da Serra, dispõe de espaços para eventos, restaurante com serviço, sala de internet, piscinas adulto e infantil, campo de futebol, salas de jogos, parque e estacionamento.

Para melhor atendimento da qualidade dos seus serviços, os hotéis e pousadas de Crato, disponibilizam de sites e telefones para contato e garantia de reservas.

\section{Considerações Finais}

O turismo local promove o desenvolvimento e crescimento da região, promovendo cadeias de produção, tornando em si, uma prática social vinculada aos mercados, mobilizando pessoas, adaptando-se ao território.

Defendemos que o turismo tem que ser integrado e participativo na localidade em que acontece, e todo o processo de planejamento das atividades turísticas devem considerar, antes de qualquer coisa que 0 turismo envolve a todo o tempo pessoas.

O mercado imobiliário torna-se forte nos seus loteamentos e empreendimentos, sobretudo quando é colocado o setor de turismo que visa privilegiar, mobilizar pessoas a vir ocuparem de um estabelecimento de hotelaria do município. Foi possível perceber que, o setor de hotelaria, cresce a cada ano, uma vez que é de suma importância investir no estabelecimento, para uma visibilidade e credibilidade maior dos seus serviços.

Treinamento dos funcionários na qualidade no atendimento também contribui para uma melhor percepção do ambiente e serviço.

O empreendedorismo no município de Crato, nos setores de hotelaria, também impacta diversos outros setores, como o comercial, de aviação, de 
turismo. Este último possibilita que gere novos empregos, como guias turísticos, afim de que seja possível promover o reconhecimento ao trajeto de turistas a conhecerem a rica visita dos geossítios do município de Crato. Pois, investir no setor de hotelaria neste município, deve levar em consideração os valores e características da região. Uma vez que, os proprietários do empreendimento são naturais da região e querem preservar seus valores regionais.

\section{Referências bibliográficas}

AMORA, Z. B. Aspectos Históricos da Industrialização do Ceará. In: SOUZA, S. (Coord). História do Ceará. Fortaleza: Demócrito Rocha, 1989, p.121128.

ASSOCIAÇÃO DE DIRIGENTES DE EMPRESAS DO MERCADO IMOBILIÁRIO. Emprego com carteira sobe na construção. 2012. Rio de Janeiro.Disponível

em<http://www.ademi.org.br/article.php3?id article=49392>. Acesso em 19 de ago de 2015.

BESERRA, F.R.S. O processo de industrialização do Cariri e o papel do Estado rumo à uma "modernização conservadora". Encontro Internacional Trabalho e Perspectivas na Formação dos Trabalhadores - Labor/UFC, 1.. Anais... Fortaleza: UFC, 2006.

BOOKING. Hoteis em Crato, Juazeiro do Norte e Barbalha. Disponível em: <http://www.booking.com/>. Acesso em: 17 de agosto de 2015.

CHIAVENATO, I. Introdução à teoria da administração: uma visão abrangente da moderna administração das organizações. 7. ed. Rio de Janeiro: Editora Campus, 2003.

ExpoCrato 2013 deverá ter um aumento de $25 \%$ nas vendas. Disponível em: <http:// blogdocrato.blogspot.com.br>. Acesso em: 13 de novembro de 2014.

FORTES, J. Mercado Imobiliário mais aquecido no interior do Ceará. Disponível em: <http://www.oestadoce.com.br>. Acesso em: 17 de agosto de 2015.

MARINHO, A. Feirão de imóveis no Cariri. Disponível em: $<$ http://perfilimobiliario.com/>. Acesso em: 17 de agosto de 2015.

MATOS, D.; BARTKIW, P.I.N. Introdução ao Mercado Imobiliário. Curso Técnico em Transações Imobiliárias - Rede E-TEC Brasil. Instituto Federal do Paraná. Paraná, 2013.

OLIVEIRA, J.C.A. A problemática ambiental e o desenvolvimento urbano na cidade do Crato (CE). Dissertação de Mestrado - PRODEMA. UFC, 1998.

OLIVEIRA, J.C.A., ABREU, R. C. Resgatando a história de uma cidade média: Crato capital da cultura. Revista Historiar. Ano II, no I, 2010.

SILVA, Nilza Costa da. Turismo de Eventos. Brasília DF, Revista Turismo: 2004. Artigo. 
Francisca Kathyane Malheiros Lins: Universidade Federal do Cariri, Crato, $\mathrm{CE}$, Brasil.

E-Mail: khatyanelins@gmail.com

Link para o currículo Lattes:

Antônio Fagundes Gomes da Silva: Universidade Federal do Cariri, Crato, CE, Brasil.

E-Mail: fagundes-gomes@hotmail.com

Link para o currículo Lattes: http://lattes.cnpq.br/9633805165150240

Francisca Laudeci Martins Souza: Universidade Federal do Cariri, Crato, CE, Brasil.

E-Mail: laudecimartins@yahoo.com.br

Link para o currículo Lattes: http://lattes.cnpq.br/5986460776339289

Data de submissão: 30 de agosto de 2016

Data de recebimento de correções: 11 de setembro de 2016

Data do aceite: 14 de setembro de 2016

Avaliado anonimamente 